\title{
Innovative Organic MEH-PPV Heterojunction Device Made by USP and PVD
}

\author{
S.E. MEFTAH, ${ }^{1,2}$ M. BENHALILIBA $\left(\mathbb{0},,^{1,2,5}\right.$ M. KALELI,${ }^{3}$ C.E. BENOUIS,,${ }^{1,2}$ \\ C.A. YAVRU, ${ }^{4}$ and A.B. BAYRAM ${ }^{4}$ \\ 1.-Physics Faculty, Oran University of Sciences and Technology USTO-MB, \\ BP1505, 31130 Oran, Algeria. 2.-Film Device Fabrication-Characterization and Application \\ FDFCA Research Group USTO, 31130 Oran, Algeria. 3.-Innovative Technologies Application \\ and Research Center, Energy Technologies Research Unit Laboratory, Department of Physics, \\ Faculty of Arts and Sciences, Süleyman Demirel University, 32260 Isparta, Turkey. 4.-Graduate \\ School of Natural and Applied Sciences, Süleyman Demirel University, 32260 Isparta, Turkey. \\ 5.—e-mail: mbenhaliliba@gmail.com
}

An Al/p-Si/poly[2-methoxy-5-(2-ethylhexoxy)-p-phenylenevinylene] (MEH$\mathrm{PPV}) / \mathrm{Ag}$ organic heterojunction has been prepared using homemade ultrasonic spray pyrolysis (USP) equipment for deposition of the organic thin film and physical vapor deposition (PVD) for the metallic contacts. The organic layer produced on glass was analyzed by optical and morphological methods. The bandgap of the organic thin film was found to be $\sim 2.03 \mathrm{eV}$ with a thickness of around $140 \mathrm{~nm}$, using ultraviolet-visible (UV-Vis) and scanning electron microscopy (SEM) characterization, respectively. The amorphous nature of the MEH-PPV polymer was confirmed by its x-ray diffraction pattern. To determine the electrical parameters, the heterojunction based on MEH-PPV was characterized by current-voltage $(I-V)$ and capacitance-voltage $(C-V)$ measurements in the dark at room temperature. The ideality factor and barrier height of the organic heterojunction were found to be $3.6 \mathrm{eV}$ and $0.56 \mathrm{eV}$ to $0.59 \mathrm{eV}$, respectively, with an average series resistance of $94.39 \Omega$, based on the $I-V$ characteristics. The barrier height was also calculated based on the capacitance-voltage measurements, yielding slightly different results due to the applied frequencies of $10 \mathrm{kHz}\left(\phi_{\mathrm{B}}=0.50\right)$ and $1 \mathrm{MHz}\left(\phi_{\mathrm{B}}=0.74\right)$, respectively.

Key words: MEH-PPV, organic heterojunction device, USP technique, optical measurements, electrical properties, series resistance

\section{INTRODUCTION}

Organic materials have attracted intensive research to study their electrical and optical characteristics for application in the electronics field due to the possibility of fabricating electronic devices with desired shapes and flexibility at low processing cost using simple methods. Configurations based on hybrid structures with organic semiconductor layers are known as organic electronic devices, e.g.,

(Received July 15, 2020; accepted January 8, 2021; published online January 31, 2021) solar cells, sensors, photodetectors, and transistors. $^{1}$ In general, organic heterojunctions have attracted great interest due to their easy manufacture and the particular optoelectronic properties obtained, allowing smooth integration with existing technologies. ${ }^{2}$ Poly[2-methoxy-5-(2-ethylhexoxy)-pphenylenevinylene] (MEH-PPV) is one of the most important derivatives of PPV with a $\pi$-conjugated system in the main chain. ${ }^{3} \mathrm{MEH}-\mathrm{PPV}$ is an emissive amorphous polymer. ${ }^{4}$ Moreover, because of the alkoxy on the phenyl group in the polymer chains, MEH-PPV can dissolve in both aromatic and nonaromatic solvents. ${ }^{5}$ To deposit organic material on $p$-type silicon, ultrasonically sprayed MEH-PPV 
was fabricated using homemade ultrasonic spray pyrolysis (USP) equipment, while silver was physically evaporated to form metallic contacts. USP is a facile approach for the synthesis of high-quality thin films for use in high-performance organic electronics, as it can prepare thin, dense, and smooth layers with fewer defects. ${ }^{6}$

In the work described herein, a metal-semiconductor-polymer (MSP) organic heterojunction structure based on MEH-PPV and $p$-type silicon was successfully fabricated. The ultimate aim of this work is to investigate its optical, structural, and electrical characteristics based on $I-V$ and $C-V$ measurements in the dark at room temperature, to determine various parameters of such heterojunction devices. The novelty of this research is the demonstration of the ability to construct such a device from organic MEH-PPV using the low-cost USP and PVD techniques.

\section{EXPERIMENTAL PROCEDURES}

\section{Starting Materials}

The chemical structure of the used conducting polymer MEH-PPV is shown in Fig. 1. Chloroform as solvent was provided by Sigma Aldrich and used without further purification. Both the silver used for the electrodes and the other chemicals utilized for cleaning (distilled water, toluene, and ethanol) were provided by Kurt J. Lesker Company. The organic molecule MEH-PPV was grown on $p$-type silicon substrate with thickness of $406 \mu \mathrm{m}$ to $457 \mu \mathrm{m}$, (111) orientation, and resistivity of $0.01 \Omega \mathrm{cm}$ to $0.02 \Omega \mathrm{cm}$.

\section{Device Fabrication}

\section{Preparation Process and Organic Layer Growth}

Glass and $\mathrm{Si}$ substrates were washed using toluene and ethanol before deposition. A homogeneous solution was prepared from $6 \mathrm{mg}$ of MEHPPV polymer dissolved in $15 \mathrm{ml}$ of chloroform, a nonaromatic solvent; the prepared solution was nearly red. The obtained solution was deposited on the silicon substrate after $2 \mathrm{~h}$ to $3 \mathrm{~h}$ of magnetic stirring at a temperature of $50^{\circ} \mathrm{C}$.

The ultrasonic spray pyrolysis (USP) process was carried out on a substrate heated to temperatures

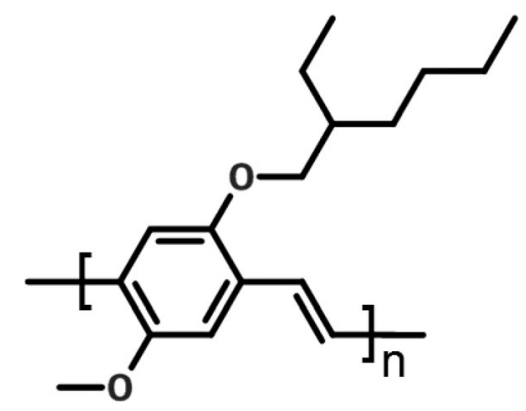

Fig. 1. Chemical structure of MEH-PPV organic polymer. between $90^{\circ} \mathrm{C}$ and $120^{\circ} \mathrm{C}$, for 35 min at a spray rate of $0.1 \mathrm{ml} / \mathrm{min}$. After deposition, the sample was annealed on a hot plate inside a glove box at $125^{\circ} \mathrm{C}$.

The USP process was repeated several times to obtain a film of the desired thickness within the 140 $\mathrm{nm}$ range. A silver grid electrode as a front contact was physically evaporated at $1100^{\circ} \mathrm{C}$ for $40 \mathrm{~min}$ using a VAKSIS 1M4T PVD setup, through a shadow mask with diameter of $1 \mathrm{~mm}$, to a thickness of $140 \mathrm{~nm}$. Figure 2 shows a cross-sectional schematic of the organic heterojunction structure based on the MEH-PPV polymer.

\section{Analysis and Measurement of Organic Layer}

Scanning electron microscopy (SEM; Quanta) was applied to measure the thickness of the as-grown organic thin layer. The optical properties of the organic layer were analyzed by ultraviolet-visible (UV-Vis) spectrometry (Lambda 20; PerkinElmer) in the wavelength range from $400 \mathrm{~nm}$ to $700 \mathrm{~nm}$. The crystalline structure was investigated by x-ray diffraction (XRD) analysis (D8 Advance; Bruker).

Current-voltage $(I-V)$ and capacitance-voltage $(C-V)$ measurements were carried out in the dark a room temperature using a Keithley 2400 source meter and Agilent 4285A impedance analyzer, respectively.

\section{RESULTS AND DISCUSSION}

\section{Structural Analysis}

To determine the structure of the as-grown thin films, XRD analysis was carried out on the MEHPPV polymer deposited on glass, revealing a broadened (002) peak at $16.04^{\circ}$ (Fig. 3). The structural parameters were determined using Scherrer formula, ${ }^{7}$

$$
D=\frac{0.94 \lambda}{\beta \cos \theta},
$$

where $D$ is the crystal size (nm), $\lambda=1.54 \AA$ is the $\mathrm{x}$ ray wavelength (in $\mathrm{nm}$ ), $2 \theta$ is the diffraction angle, and $\beta(15.94)$ is the full-width at half-maximum (FWHM) measured in $2 \theta$ and expressed in radians. The average crystalline size of the thin film of MEHPPV polymer was $11.1 \mathrm{~nm}$, close to previous work that reported a grain size of $12.3 \mathrm{~nm} .^{8}$ The XRD profile of the MEH-PPV thin layer showed a broadened crystalline peak with a FWHM of $15.94^{\circ}$, indicating a roughly amorphous nature of the polymer., 10

\section{Optical Properties of the Thin Film}

Figure 4 shows the optical absorbance spectrum in the wavelength range from $400 \mathrm{~nm}$ to $700 \mathrm{~nm}$ for the MEH-PPV thin film deposited on glass substrate after annealing at $125^{\circ} \mathrm{C}$. The absorbance profile presents a broad peak at $511 \mathrm{~nm}$. The optical 


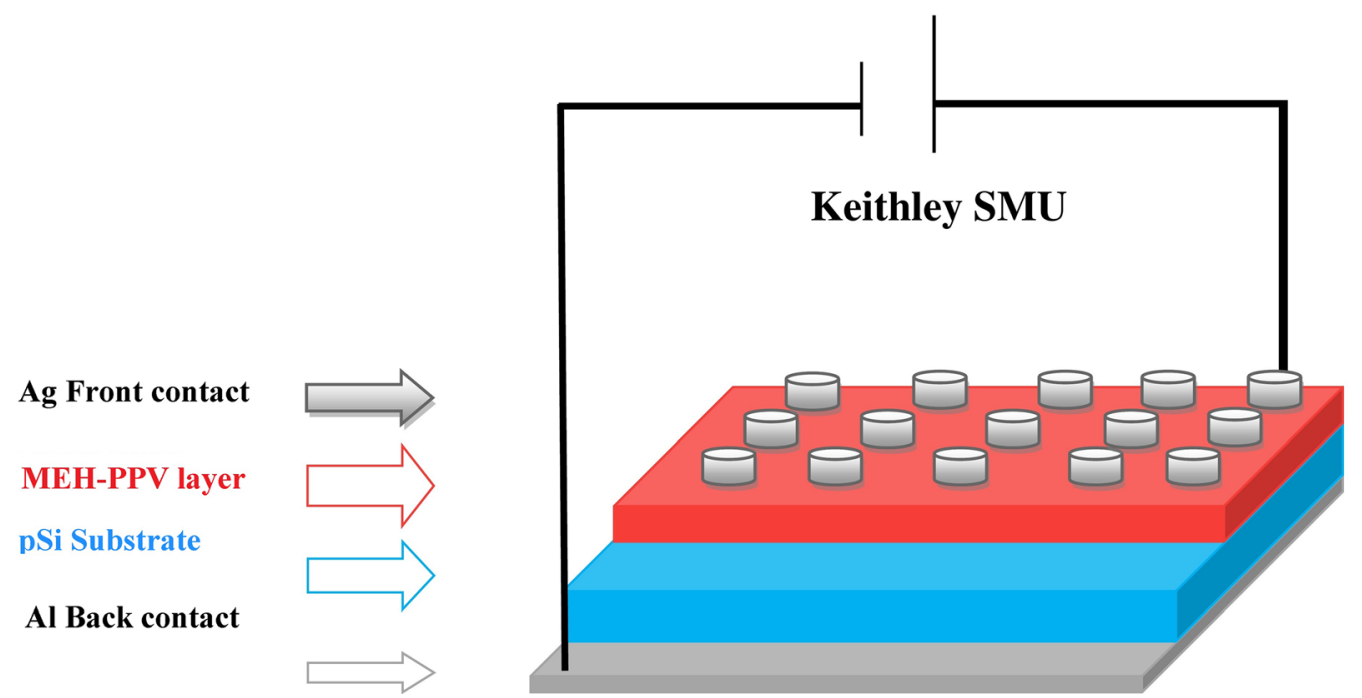

Fig. 2. Schematic cross-section of obtained Al/p-Si/MEH-PPV/Ag structure.

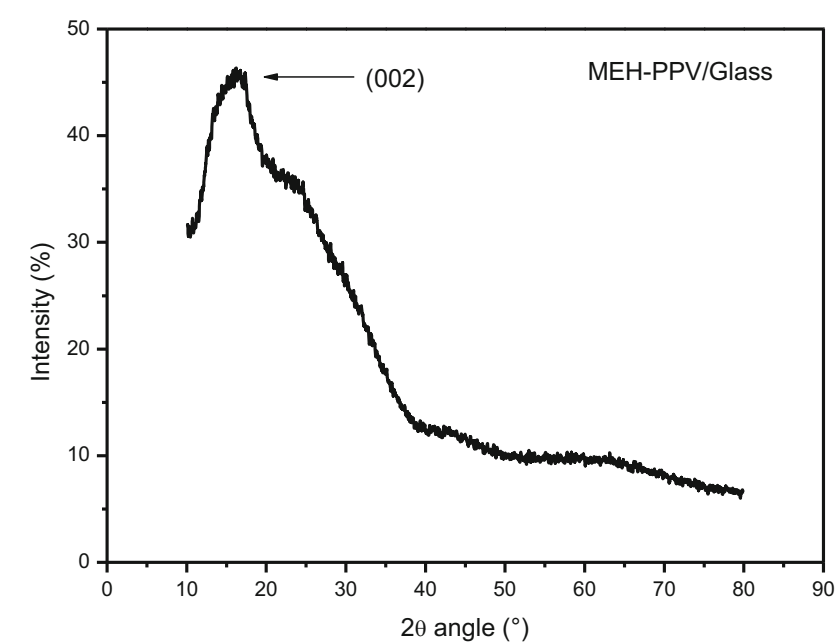

Fig. 3. XRD profile of organic MEH-PPV polymer deposited on glass substrate.

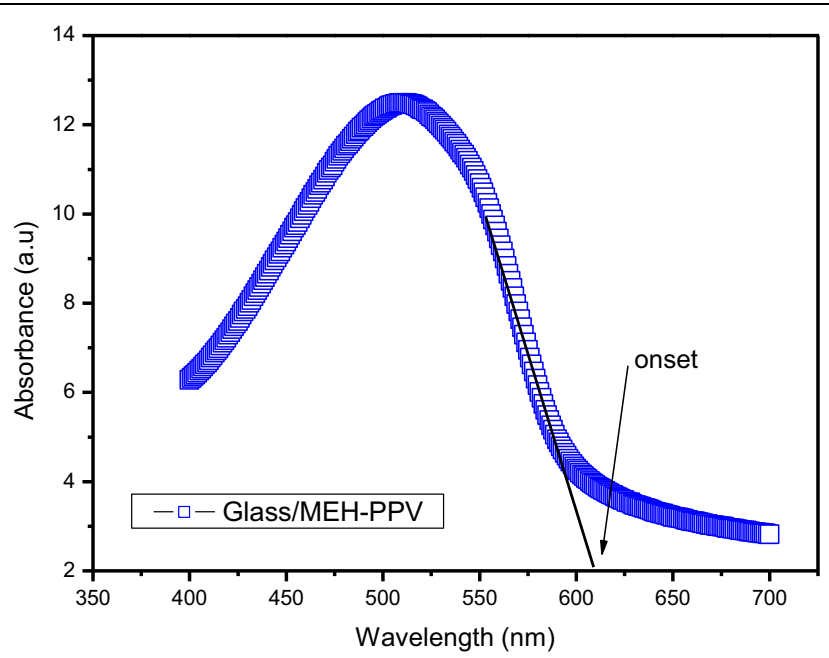

Fig. 4. Absorbance versus wavelength for the sprayed MEH-PPV polymer thin layer. bandgap was determined using the extrapolation of the absorbance plot according to the relation ${ }^{11}$

$$
E_{\text {onset }}^{\text {opt }}=\frac{h c}{\lambda_{\text {onset }}}
$$

where $h$ is Planck's constant and $c$ is the speed of light in vacuum. The onset wavelength for the MEH-PPV thin film fabricated in chloroform was $611 \mathrm{~nm}$, giving a $E_{\mathrm{g}}^{\text {opt }}$ value of $2.03 \mathrm{eV}$. The calculated value can be confirmed using the BeerLambert law as follows: ${ }^{12}$

$$
\alpha=2.303 A / d
$$

where $d$ is the layer thickness and $A$ is the absorption ratio value. The bandgap value was estimated from the fundamental absorption edge of the films. For the linear plot of $\alpha h v$ versus $h v$ over a wide range of photon energies, the absorption coefficient can be expressed as ${ }^{12,13}$

$$
\alpha h v=B\left(h v-E_{\mathrm{g}}\right)^{p},
$$

where $B$ is a constant, $E_{\mathrm{g}}$ is the bandgap energy of the material, and $p$ takes the value $1 / 2$ for a direct transition, with the absorption plot showing a single slope. ${ }^{14}$ Figure 5 shows the plot of $(\alpha h v)^{2}$ versus $h v$. The intercept of the extrapolation of the straight line to the energy axis gives a $E_{\mathrm{g}}^{\mathrm{opt}}$ value of $2.02 \mathrm{eV}$ for the MEH-PPV thin film. A value of $2.21 \mathrm{eV}$ is reported in literature, although it is difficult to make a direct comparison due to the various deposition methods, measurement methods and equipment, and sample preparation techniques applied. ${ }^{10}$

The UV-Vis spectrum of the MEH-PPV film exhibited a single peak at $\sim 511 \mathrm{~nm}$, which can be attributed to the $\pi-\pi^{*}$ transition of the aromatic polymer MEH-PPV. ${ }^{16}$ 


\section{SEM Results}

SEM images were taken at several resolutions. As depicted in Fig. 6, a homogeneous MEH-PPV film of good quality was deposited on the glass substrate, exhibiting a smooth surface and good film-substrate adhesion; no irregularities were observed, and the layer was essentially flat. However, the thickness of the sample was not constant, varying around an average of $140 \mathrm{~nm}$ as indicated by the arrow in Fig. 6. This variation in the thickness is due to our homemade USP system. The SEM analysis confirmed that the polymer layer had a homogeneous, smooth surface.

\section{Current-Voltage (I-V) Characteristics of $\mathrm{Al} /$ p-Si/MEH-PPV/Ag Structure}

To investigate the electrical behavior of the asfabricated $\mathrm{Al} / p$-Si/MEH-PPV/Ag organic

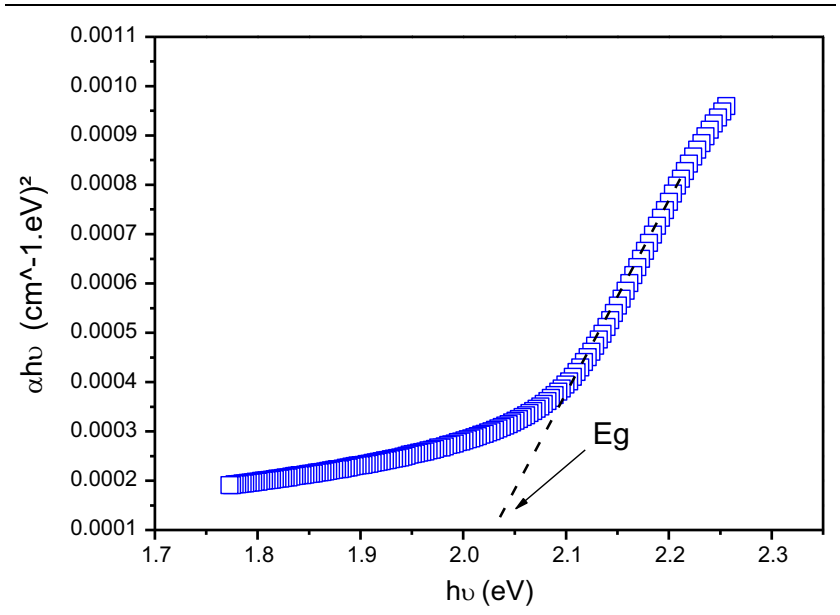

Fig. 5. $(\alpha h v)^{2}$ versus $h v$ for the sprayed MEH-PPV layer. The value of $E_{\mathrm{g}}$ is indicated.

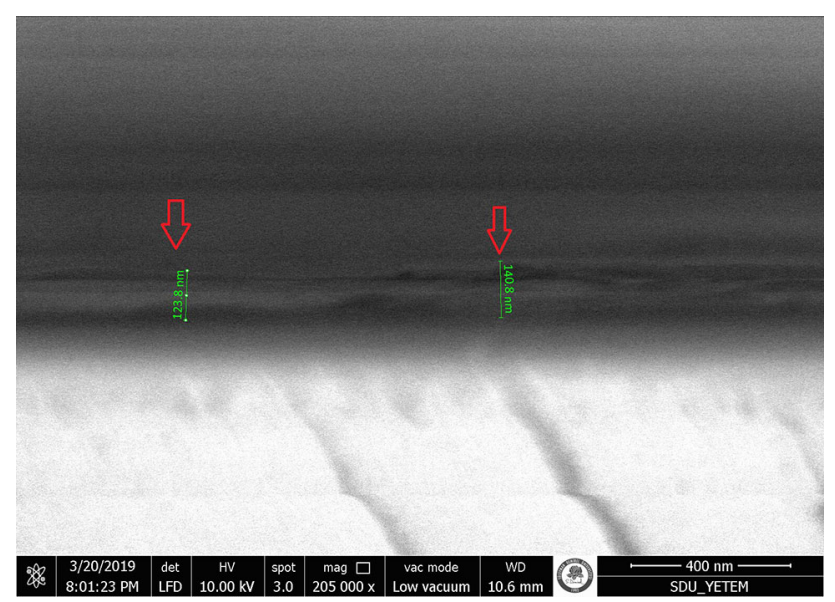

Fig. 6. Cross-sectional SEM image of MEH-PPV with thickness of $123 \mathrm{~nm}$ and $140 \mathrm{~nm}$, taken at magnification of 205,000x at $10 \mathrm{kV}$. The thickness of the organic layer is indicated by arrows. heterostructure, electrical parameters including $n$, $R_{\mathrm{s}}$, and $\phi_{\mathrm{B}}$ were obtained using the forward-bias $I-$ $V$ results, and the Cheung and Nord functions.

The experimental semilogarithmic reverse- and forward-bias $I-V$ characteristics of the $\mathrm{Al} / p-\mathrm{Si} /$ MEH-PPV/Ag organic heterostructure in the dark at room temperature are shown in Fig. 7.The current-voltage curve is linear on a semilogarithmic scale in the moderate forward-bias voltage region. According to thermionic emission theory, the current can be expressed as ${ }^{16}$

$$
I=I_{0} \exp \left[\frac{q\left(V-I R_{\mathrm{s}}\right)}{n k T}\right]
$$

where $I$ and $V$ are the measured current and applied voltage of the diode, and $I_{0}$ is the reverse saturation current, which can be expressed as ${ }^{17}$

$$
I_{0}=A A^{*} T^{2} \exp \left(-\frac{q \phi_{\mathrm{b}}}{k T}\right)
$$

where $A$ is the effective diode area, $A^{*}$ is the effective Richardson constant (equal to $32 \mathrm{~A} \mathrm{~cm}^{-2}$ $\mathrm{K}^{-2}$ for $p$-type silicon), $T$ is the absolute temperature in Kelvin, $q$ is the electron charge, $n$ is the ideality factor, and $\phi_{\mathrm{b}}$ is the zero-bias barrier height. The barrier height is the difference between the edge of the majority-carrier band of the semiconductor and the Fermi level at the interface. ${ }^{18}$ The diode equation based on thermionic emission (TE) theory indicates a linear $I-V$ plot. The value of $I_{0}$ can be extracted and inserted into Eq. (5) to calculate $\phi_{\mathrm{b}}$, which can be expressed as ${ }^{19}$

$$
\phi_{\mathrm{b}}=\frac{k T}{q} \ln \left(\frac{A A^{*} T^{2}}{I_{0}}\right)
$$

The ideality factor $n$ is greater than unity and shows the deviation between the experimental $I-V$ characteristics of the organic device and ideal $\mathrm{TE}$

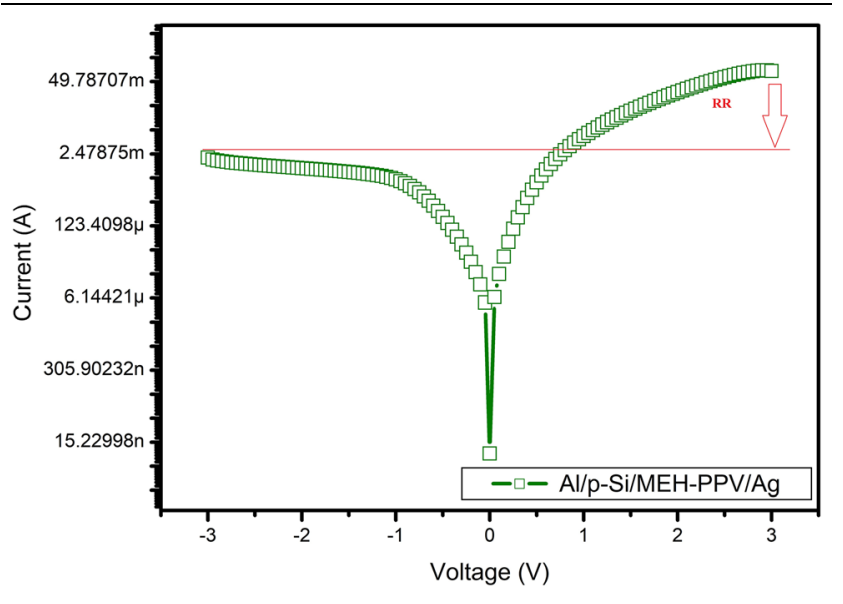

Fig. 7. Semilogarithmic plot of current-voltage characteristics of $\mathrm{Al} /$ P-MEH-PPV/Ag organic device in the dark at room temperature, including the rectification ratio $(\mathrm{RR})$. 
theory (for which $n=1$ ); it can be calculated using the relation ${ }^{20}$

$$
n=\frac{q}{k T} \frac{\mathrm{d} V}{\mathrm{~d}(\ln I)},
$$

where $k$ is the Boltzmann constant, $T$ is the absolute temperature ( $300 \mathrm{~K})$, and $q$ is the electron charge. In the ideal case, the ideality factor is equal to 1 . However, mostly $n$ is higher than unity $(n>1)$ and is found to be 3.6, which may be due to the native oxide layer on electrodes ${ }^{21}$ or other effects, such as the inhomogeneous thickness of the deposited film, the organic layer effect on the structure, etc. ${ }^{12}$ It is observed that the rectification ratio (RR) of the MEH-PPV organic heterojunction is about 36.26. Cheung's functions, given in Eq. (9), are used to evaluate $n, R_{\mathrm{s}}$, and $I_{\mathrm{b}}$; these parameters are significant and influence the quality of the electrical conduction in the structure: ${ }^{22,23}$

$$
\begin{gathered}
\frac{\mathrm{d} V}{\mathrm{~d}(\ln I)}=I R_{\mathrm{s}}+n\left(\frac{k T}{q}\right), \\
H(I)=V-\left(\frac{n k T}{q}\right) \ln \left(\frac{I}{A A^{*} T^{2}}\right),
\end{gathered}
$$

Here, $H(I)$ can be written as

$$
H(I)=I R_{\mathrm{s}}+n \phi_{\mathrm{B}} .
$$

The experimental $\mathrm{d} V / \mathrm{d} \ln I$ versus $I$ plot for the studied structure is presented in Fig. 8. To define $H(I)$ from Eq. (10), it is necessary to set the values of $n$ and $R_{\mathrm{s}}$ from Eq. (9) using the intercept and slope of the curve fit to a straight line. The slope and $y$ axis intercept of the $H(I)$ versus $I$ plot (straight line) shown in Fig. 9 gives the values of $R_{\mathrm{s}}$ and $n \phi_{\mathrm{B}}$ values using Eq. (11). Having obtained the two values of $R_{\mathrm{s}}$ of $94.39 \Omega$ and $95.70 \Omega$ using the $\mathrm{d} V / \mathrm{dln}$ $I$ versus $I$ and $H(I)$ versus $I$ plots, respectively, it can

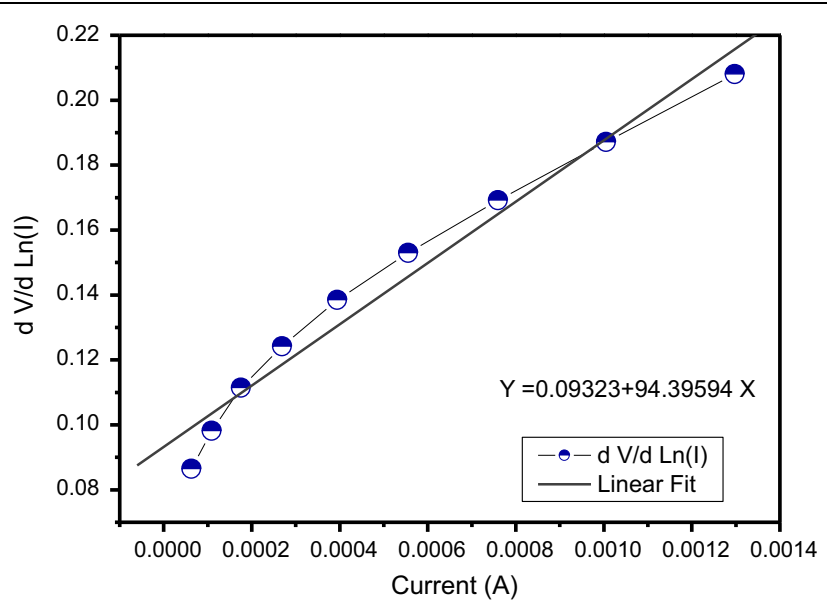

Fig. 8. Experimental $d V / d(\ln /)$ versus / plot for $\mathrm{Al} / \mathrm{p}$-Si/MEH-PPV/Ag organic MSP heterojunction diode in the dark at room temperature. The linear fit and its equation are indicated. be said that Cheung's method is a consistent approach that is in good agreement with the values. To compare the $R_{\mathrm{s}}$ values obtained using Cheung's function with the average value of $95.04 \Omega$ obtained using the Norde functions, a third approach is used, defined by the expression ${ }^{21}$

$$
F(V)=\frac{V}{\gamma}-\frac{k T}{q} \ln \left(\frac{I(V)}{A A^{*} T^{2}}\right),
$$

where $\gamma$ is the first integer greater than the ideality factor of the diode, and $I$ and $V$ are obtained from the forward-bias $I-V$ characteristics. The barrier height of the structure is given by ${ }^{24}$

$$
\phi_{\mathrm{B}}=F\left(V_{0}\right)+\frac{V_{0}}{\gamma}-\frac{k T}{q},
$$

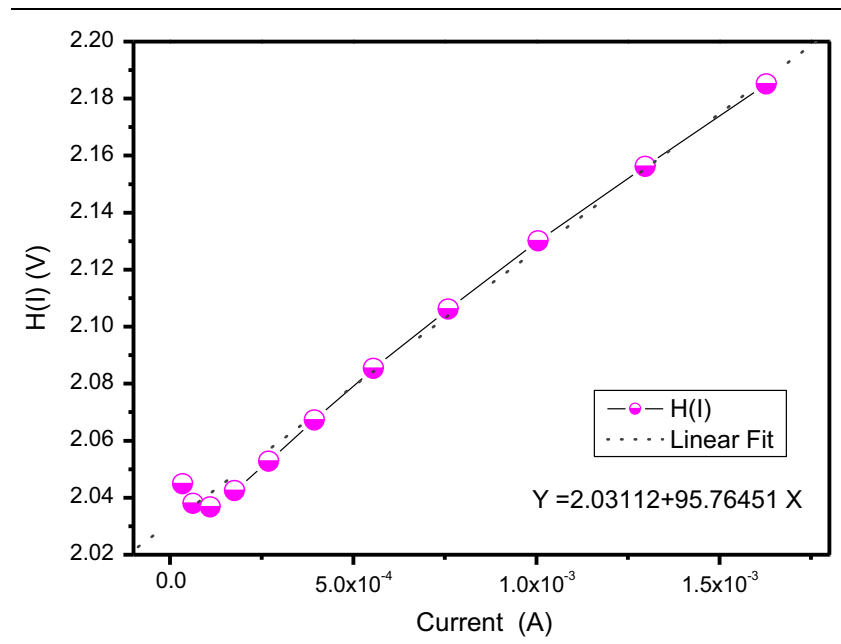

Fig. 9. Experimental $H(I)$ versus I plot for Al/p-Si/MEH-PPV/Ag organic MSP diode in the dark at room temperature. The linear fit and its equation are displayed.

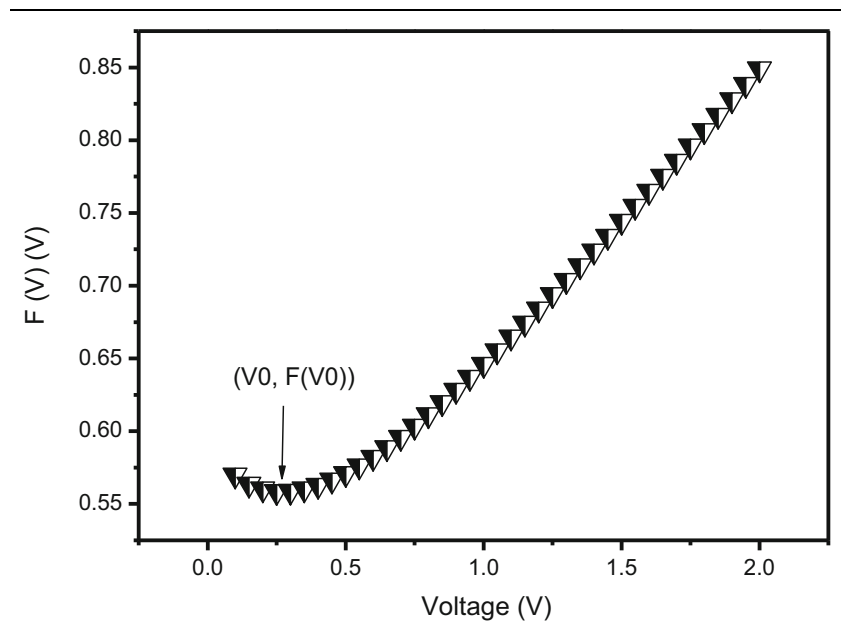

Fig. 10. Norde function versus voltage obtained by plotting the forward-bias $l-V$ characteristics of the MEH-PPV organic device in the dark at room temperature. The minimum occurs at $V_{0}$ and $F\left(V_{0}\right)$. 
where $F\left(V_{0}\right)$ is the minimum value taken from the plot of $F(V)$ versus $V$, as shown in Fig. 10 , and $V_{0}$ is the corresponding voltage. Moreover, from the Norde function, $R_{\mathrm{s}}$ is obtained using the relation ${ }^{25}$

$$
R_{\mathrm{s}}=\frac{k T(\gamma-n)}{q I_{\min }},
$$

where $I_{\min }$ is the minimum value of the current corresponding to the value $V_{0}$. Using the extracted values of $F\left(V_{0}\right), V_{0}$, and $I_{\min }$ from the $F(V)$ versus $V$ plot, the values of $R_{\mathrm{S}}$ and $\phi_{\mathrm{B}}$ are then determined.

The values of the series resistance and barrier height obtained using Cheung's approach and Norde method are presented in Table I. Although the values obtained using the three methods are extracted from different regions of the forward-bias $I-V$ characteristic, the values obtained by the previous methods are in very good agreement, with a slight discrepancy that can be neglected. Indeed, the relevant results in this investigation are precise and approximately similar for the barrier height and series resistance.

\section{Capacitance-Voltage Characteristics in the Dark at Room Temperature}

Capacitance-voltage measurements were carried out at different experimental frequencies (from $10 \mathrm{kHz}$ to $1 \mathrm{MHz}$ ) in the dark at room temperature. The built-in voltage $V_{\mathrm{bi}}$ and space charge density are significant parameters describing the behavior of the $\mathrm{Al} / p$-Si/MEH-PPV/Ag organic heterostructure and can be determined from the measured capacitance $C$ by plotting $1 / C^{2}$ versus $V$, as described in this subsection. Figure 11 shows the $C-V$ plots of the $\mathrm{Al} / p$-Si/MEH-PPV/Ag structure obtained at two different frequencies of $10 \mathrm{kHz}$ and $1 \mathrm{MHz}$, revealing symmetric curves that overlap below $\sim 0.7 \mathrm{~V}$ but differ thereafter, indicating that the capacitance is a function of both voltage and frequency. Note that the $C-V$ curve is higher at the lower frequency.

To determine the barrier height and the interface state density by the capacitance-voltage method, the capacitance is represented by the classic MottSchottky relation, expressed $\operatorname{as}^{26}$

$$
\frac{1}{C^{2}}=\frac{2\left(V_{\mathrm{D}}-V\right)}{q \varepsilon_{\mathrm{S}} N_{\mathrm{D}} A^{2}}
$$

where $V_{\mathrm{bi}}$ is the built-in potential, $\varepsilon_{\mathrm{S}}$ is the dielectric constant of the $p$-type silicon $\left(\varepsilon_{\mathrm{S}}=11.7\right)$, and $q$ is the elementary charge. The doping concentration $N_{\mathrm{D}}$ and diffusion potential $V_{\mathrm{D}}$ values for the diode can be calculated from the intercept and slope of Fig. 12, yielding values of $2.8 \times 10^{13} \mathrm{~cm}^{-3}$ and $0.21 \mathrm{~V}$, respectively, at a frequency of $10 \mathrm{kHz}$ and $5.14 \times 10^{20} \mathrm{~cm}^{-3}$ and $1.88 \mathrm{~V}$ at $1 \mathrm{MHz}$. The barrier height of the $\mathrm{Al} / p$-Si/MEH-PPV/Ag heterojunction device can be expressed as ${ }^{27}$

$$
\phi_{\mathrm{B}}=V_{\mathrm{bi}}+\frac{k T}{q} \ln \left(\frac{N_{\mathrm{C}}}{N}\right),
$$

where $N$ is the density of states in the conduction band at room temperature and $V_{\mathrm{bi}}$ is the intercept voltage. ${ }^{27}$ At $10 \mathrm{kHz}$ and $1 \mathrm{MHz}$, the built-in voltage is found to be $0.14 \mathrm{~V}$ and $0.82 \mathrm{~V}$, respectively; utilizing Eq. (16), the barrier heights of the heterojunction structure are found to be $\sim 0.50 \mathrm{~V}$ and $\sim$ $0.74 \mathrm{~V}$ at both frequencies, using the $C^{2}$ versus $V$ plots and Eq. (15). Figure 11 shows typical $C-V$ curves of the organic structure at the two distinct frequencies of $10 \mathrm{kHz}$ and $1 \mathrm{MHz}$, demonstrating the bias voltage and frequency dependence. ${ }^{28}$ As can be seen, the capacitance increases in parallel in the first region for both frequencies, then reaches a maximum value at each frequency; this tendency is due to the existence of various kinds of interface states. $^{29}$ No impact of frequency is observed in either the deep depletion $(-2 \mathrm{~V}<V<-0.5 \mathrm{~V})$ or depletion $(-0.5<V 0.4 \mathrm{~V})$ regimes, but the two curves separate from $0.4 \mathrm{~V}$, with the capacitance becoming larger at the lower frequency in the

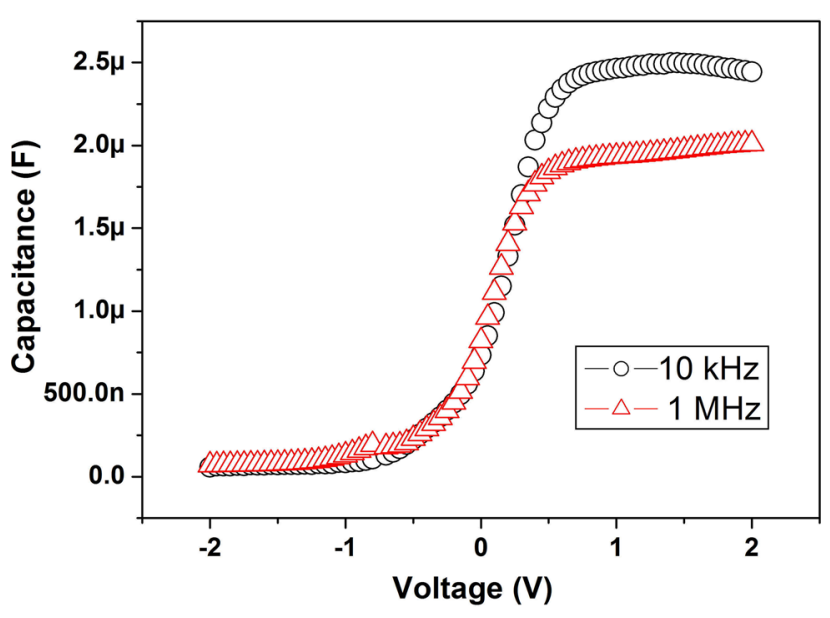

Fig. 11. Capacitance-voltage characteristics of $\mathrm{Al} / p-\mathrm{Si} / \mathrm{MEH}-\mathrm{PPV} /$ $\mathrm{Ag}$ organic device at two frequencies, $10 \mathrm{kHz}$ and $1 \mathrm{MHz}$.

\begin{tabular}{|c|c|c|c|c|c|c|c|c|}
\hline & \multicolumn{2}{|c|}{$\mathrm{d} V / \mathrm{d} \ln I$} & \multicolumn{2}{|c|}{ Cheung method } & \multicolumn{2}{|c|}{ Norde method } & \multicolumn{2}{|c|}{ Capacitance-Voltage } \\
\hline & $N$ & $R_{\mathrm{s}}(\Omega)$ & $\boldsymbol{R}_{\mathrm{s}}(\boldsymbol{\Omega})$ & $\phi_{\mathbf{B}}(\mathbf{e V})$ & $\boldsymbol{R}_{\mathrm{s}}(\boldsymbol{\Omega})$ & $\phi_{\mathbf{B}}(\mathrm{eV})$ & $\phi_{\mathrm{B}}(\mathrm{eV})(10 \mathrm{kHz})$ & $\phi_{\mathrm{B}}(\mathrm{eV})(\mathbf{M H z})$ \\
\hline $\mathrm{Al} / p-\mathrm{Si} / \mathrm{MEH}-\mathrm{PPV} / \mathrm{Ag}$ & 3.60 & 94.39 & 95.70 & 0.56 & 94.60 & 0.59 & 0.50 & 0.74 \\
\hline
\end{tabular}

Table I. Experimental values of ideality factor, series resistance, and barrier height extracted by $\mathrm{d} V / \mathrm{dln} I$, Cheung, Norde, and $C-V$ characteristic methods 

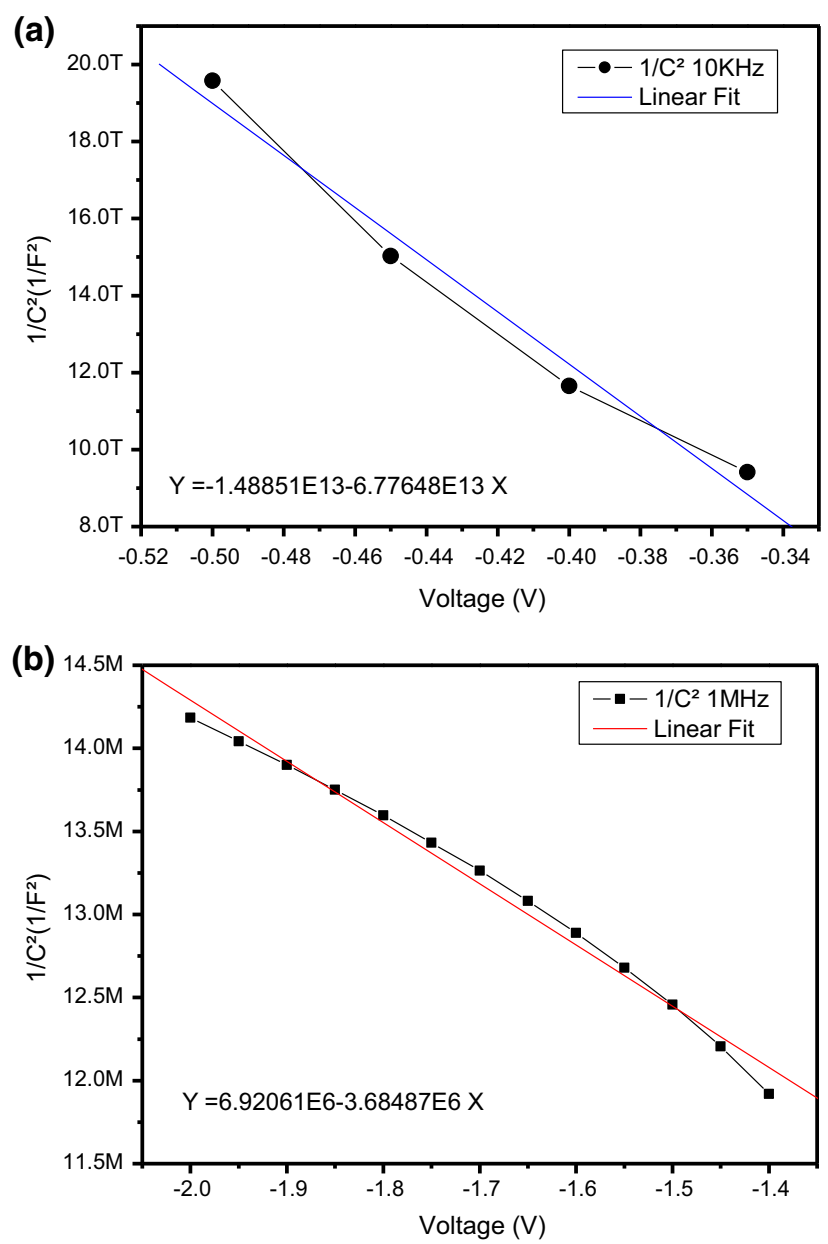

Fig. 12. $1 / C^{2}$ versus $V$ for $\mathrm{Al} / \mathrm{p}$-Si/MEH-PPV/Ag organic device at (a) $10 \mathrm{kHz}$ and (b) $1 \mathrm{MHz}$ in the dark at room temperature. The linear fit and its equation are indicated.

accumulation regime $(0.4 \mathrm{~V}<V<2 \mathrm{~V})$. To provide further understanding of the capacitance of the device, $C^{-2}$ is plotted versus $V$ in Fig. 12 , revealing straight lines in the reverse voltage region at both $10 \mathrm{kHz}$ and $1 \mathrm{MHz}$, which indicates uniform behavior of the charge density in the depletion region.

\section{Transport Mechanism in Al/p-Si/P3HT/Ag MSP Heterojunction Diode}

When the ideality factor exceeds unity $(n>1)$, the transport mechanism is no longer dominated by thermionic emission. To comprehend which mechanisms control the conduction in the $\mathrm{Al} / p$-Si/MEH-PPV/ $\mathrm{Ag}$ structure, the log-log forward-bias current-voltage plot is shown in Fig. $13,^{30}$ displaying power-law behavior of the current according to the expression ${ }^{31}$

$$
I \alpha V^{m},
$$

where $m$ changes with the injection level, likewise being identified with the distribution of trapping centers that differs with the injection level. ${ }^{31}$ In Fig. 13, two straight line sections are noted,

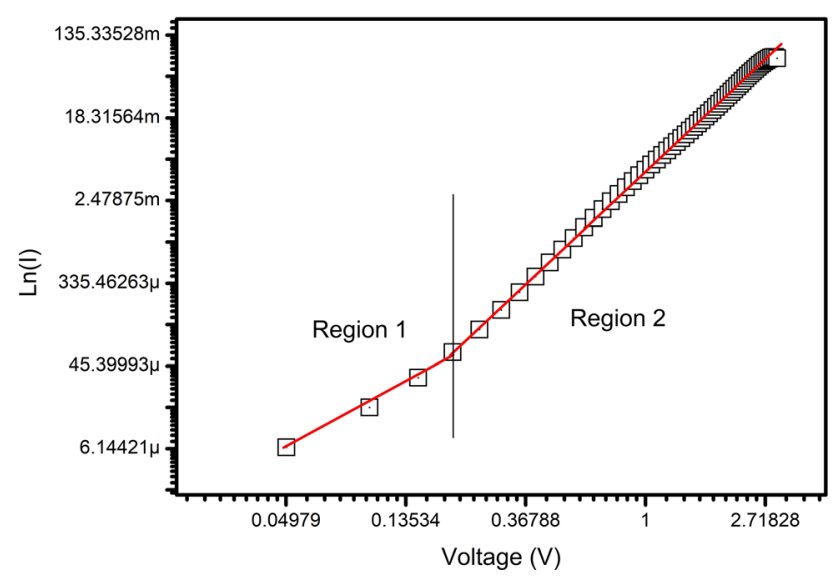

Fig. 13. Log I versus Log $V$ characteristic of $\mathrm{Al} / p-\mathrm{Si} / \mathrm{MEH}-\mathrm{PPV} / \mathrm{Ag}$ organic device in the dark at room temperature; the solid red line indicates the two different regions.

corresponding to $m$ values of 1.6 and 2.7 for the first $(V<0.2 \mathrm{~V})$ and second $(V>0.2 \mathrm{~V})$ region, respectively.

In the first region, the dominant mechanism is Ohmic at lower voltage, with the current being proportional to the voltage. ${ }^{32,33}$ In the second region, the power-law dependence demonstrates that the current is space-charge limited and that the impact of traps on the conduction current is dominated by the exponential distribution of trapping levels. ${ }^{34,35}$

\section{CONCLUSIONS}

An $\mathrm{Al} / p$-Si/MEH-PPV/Ag heterojunction device was fabricated using USP and PVD techniques. Optical and morphological characterization were carried out. The XRD profile of the MEH-PPV thin film revealed its amorphous nature. SEM analysis revealed an average thickness for the deposited organic film of $140 \mathrm{~nm}$. The bandgap value was confirmed to be $\sim 2.03 \mathrm{eV}$ by two calculations, in good agreement with literature despite the variety of methods used. Electrical device parameters such as the ideality factor $\mathrm{n}$, barrier height $\phi_{\mathrm{B}}$, and average series resistance $R_{\mathrm{s}}$ of the $\mathrm{Al} / \mathrm{p}-\mathrm{Si} / \mathrm{MEH}$ PPV/Ag structure were obtained using different calculation methods from current-voltage and capacitance-voltage measurements in the dark at room temperature. The values of $n, \phi_{\mathrm{B}}$, and $R_{\mathrm{S}}$ are in good agreement with previous values. Detailed study on the conduction mechanism is also reported. Excellent agreement was found between the values obtained using the four methods including Cheung's, Norde's, and the capacitance-voltage method.

The diffusion potential is found to be 0.50 and 0.74 at two measurement frequencies of $10 \mathrm{kHz}$ and $1 \mathrm{MHz}$, respectively, with doping concentrations of $2.8 \times 10^{13} \mathrm{~cm}^{-3}$ and $5.14 \times 10^{20} \mathrm{~cm}^{-3}$. The results of the present experimental investigation could be 
used to optimize devices based on MEH-PPV or other $p$-type organic materials for microelectronics applications.

\section{ACKNOWLEDGEMENTS}

The work is included in the PRFU project under Contract No. B00L02UN310220180011 of Oran University of Sciences and Technology USTO-MB. https://www.mesrs.dzhttps://www.mesrs.dz, and ht tps://www.univ-usto.dz. http://www.prfu-mesrs.dz/. https://www.mendeley.com/impact/mostefa-benhali liba. https://orcid.org/0000-0001-6507-3663. https:// orcid.org/0000-0002-3290-2020, https://orcid.org/00 00-0002-7364-8559. https://orcid.org/0000-0003-493 2-0382. We dedicate this work to every researcher in the world, especially in biology and virology, to all doctors, and all those working in nursing and pharmacy during the COVID-19 pandemic.

\section{CONFLICT OF INTEREST}

The authors declare that they have no conflicts of interest.

\section{REFERENCES}

1. D. Hewidy, A.-S. Gadallah, and G.A. Fattah, Phys. B Condens. Matter. 507, 46 (2017).

2. A. Petrella, M. Tamborra, M. Lucia Curri, P. Cosma, M. Striccoli, D. Cozzoli, and A. Agostiano J. Phys. Chem. B 109 , 4 (2005).

3. H. Zhang, X. Lu, Y. Li, X. Ai, X. Zhang, and G. Yang, J. Photochem. Photobiol. Chem. 147, 1 (2002).

4. M.I. Sluch, C. Pearson, M.C. Petty, M. Halim, and I.D.W. Samuel, Synth. Met. 94, 285 (1998).

5. N. Juhari, W.H.A. Majid, and A.I. Zainol. Procedia Eng. 53, 354 (2013).

6. H.-C. Hsieh, J. Yu, S.-P. Rwei, K.-F. Lin, Y.-C. Shih, and L. Wang, Thin Solid Films 659, 41 (2018).

7. H. Derouiche, H.B. Miled, and A.B. Mohamed, Phys. Status Solidi A207, 479 (2010).

8. I.M. Ibrahim and S.I. Sharhan, Dig J. Nanomater. Biostruct. 14, 93 (2019)

9. I.M. Ibrahim and S.I. Sharhan, Nano Hybrids Compos. 25, 12 (2019).

10. J.S. Shankar, S.A. Kumar, B.K. Periyasamy, and S.K. Nayak, Polym. Plast. Technol. Mater. 58, 189 (2019).
11. F.C. Correia, T.C.F. Santos, J.R. Garcia, L.O. Peres, and S.H. Wang, J. Braz. Chem. Soc. 26, 84 (2014).

12. S.E. Meftah, M. Benhaliliba, M. Kaleli, C.E. Benouis, C.A Yavru, and A.B. Bayram, Phys. B Condens. Matter. 593, 412238 (2020).

13. Y. Aydogdu, F. Yakuphanoglu, A. Aydogdu, E. Tas, and A. Cukurovali, Solid State Sci. 4, 879 (2002).

14. F. Yakuphanoglu, M. Arslan, and S.Z. Yildı, Opt. Mater. 27, 153 (2005)

15. L. Fugikawa-Santos, R.C. Faria, L. Gaffo, L.M. Carvalho, R.M. Faria, and D. Gonçalves, Electrochim. Acta 52, 287 (2007).

16. N.Z. Yahya, and M. Rusop, J. Nanomater. 2012, 1 (2012).

17. M.E. Aydin, F. Yakuphanoglu, J.-H. Eom, and D.-H. Hwang, Phys. B Condens. Matter 387, 239 (2007).

18. M. Okutan, and F. Yakuphanoglu, Microelectron. Eng. 85, 646 (2008).

19. F. Yakuphanoglu, M. Kandaz, and B.F. Senkal, Thin Solid Films 516, 8793 (2008).

20. F. Yakuphanoglu, E. Basaran, B.F. Şenkal, and E. Sezer, J. Phys. Chem. B 110, 16908 (2006).

21. Z. Ahmad and M.H. Sayyad, Phys. E Low Dimens. Syst. Nanostruct. 41, 631 (2009).

22. F. Yakuphanoglu, and B.F. Şenkal, Synth. Met. 159, 311 (2009).

23. F. Yakuphanoglu and S. Okur, Microelectron. Eng. 87, 30 (2009).

24. H. Norde, J. Appl. Phys. 50, 5052 (1979)

25. Ş Karataş, Ş Altındal, A. Türüt, and M. Çakar, Phys. B Condens. Matter. 392, 43 (2007).

26. Y. Caglar, M. Caglar, S. Ilican, and F. Yakuphanoglu, Microelectron. Eng. 86, 2072 (2009).

27. S. Okur, F. Yakuphanoglu, M. Ozsoz, and P.K. Kadayifcilar, Microelectron. Eng. 86, 2305 (2009).

28. W.P. Kang, J.L. Davidson, Y. Gurbuz, and D.V. Kerns, J. Appl. Phys. 78, 1101 1995).

29. S. Zeyrek, E. Acaroğlu, S Altındal, S. Birdoğan, and M.M. Bülbül, Curr. Appl. Phys. 13, 1225 (2013).

30. T.B. Jomaa, L. Beji, A. Ltaeif, and A. Bouazizi, Mater. Sci. Eng. C 26, 530 (2006).

31. M. Echabaane, A. Rouis, I. Bonnamour, and H. Ben Ouada, Measurement, 46, 2263 (2013).

32. M. Soylu and B. Abay, Phys. E Low Dimens. Syst. Nanostruct. 43534 (2010).

33. M. Benhaliliba, C. E. Benouis, M. S. Aida, and A. Ayesha Mariam, J. Semicond. 38, 64004 ( 2017).

34. A.S. Riad, Phys. B Condens. Matter., 270, 148 (1999).

35. F. Yakuphanoglu, Sens. Actuators Phys., 147, 104 (2008).

Publisher's Note Springer Nature remains neutral with regard to jurisdictional claims in published maps and institutional affiliations. 